\title{
Analysis on the Combustion Process of the Ethanol - Diesel Direct Injection Engine with Simultaneous Diesel and Ethanol Injection (with Ethanol Injection Starting Point Earlier than the Diesel Injection Starting Point)
}

\author{
Yu Liang, Liying Zhou, Guwen Yao, Xiaoke Ding, Jiang Dong, TingFeng Qu \\ College of Mechanical Engineering, Guiyang University, Guiyang 550005, China \\ Corresponding author e-mail: zhouliying0330@163.com
}

Keywords: diesel engine, ethanol, ethanol - diesel direct injection, combustion process, 3D simulation

\begin{abstract}
A set of GDI system for ethanol injection is installed on a F188 diesel engine, and the diesel supply system of the original diesel engine is used for diesel injection. The computational fluid dynamics software FIRE is adopted to establish a 3D combustion model of the ethanol - diesel direct injection engine. The total heat energy of the fuel is equivalent to that of the original diesel engine under the same condition. As the diesel injection starting point is $344^{\circ} \mathrm{CA}$ and there is simultaneous diesel and ethanol injection, the ethanol injection starting points at $344^{\circ} \mathrm{CA}, 338^{\circ} \mathrm{CA}$, $332^{\circ} \mathrm{CA}, 326^{\circ} \mathrm{CA}$ and $320^{\circ} \mathrm{CA}$ are subject to $3 \mathrm{D}$ simulation for fuel injection, mixed gas formation and combustion and pollutant formation process. The results show that, the earlier the ethanol injection is, the steeper the heat release rate curve during the initial combustion period, the higher the peak value, and the shorter the heat release duration are, and the higher the maximum combustion pressure, the headmost phase of the maximum combustion pressure and the more obvious the premixed combustion are. Earlier ethanol injection starting point and quicker rise of the temperature curve of the cylinder bring the headmost phase of the highest average temperature in the cylinder, and higher average temperature in the cylinder brings higher NO concentration. The ethanol injection starting point shall be earlier than the diesel injection starting point injection, for it is the most favorable for reducing soot generation.
\end{abstract}

\section{Introduction}

Our country has formed a certain scale in the preparation of ethanol with non-food crops including cassava, sweet sorghum and xylose residue [1], and the technology of preparing the ethanol with wood lignocellulose including forestry and agricultural residues is becoming more and more mature [2]. The ethanol contains 34.7\% oxygen, its octane value is high and combustion speed is fast, so it is a highly efficient and clean renewable energy source. In addition, it is not only a kind of high quality fuel, but also a kind of fuel quality improvement agent with high quality. In recent years, the price of petroleum has gradually increased in the fluctuation, and the ethanol consumption has been increased year by year. Therefore, the energy supply diversification strategy represented by alternative energy, such as ethanol, has become a trend of China's energy policy and has a broad application prospect in China [3].

As ethanol is not mutually soluble with diesel, its application in the diesel engine is not as easy as its application in the gasoline engine [4]. If adopting the pre-mixing of the ethanol and diesel, the proportion of the ethanol shall be kept below $10 \%$ to keep the mixed fuel uniformity for a longer time, and a certain cosolvent shall be added during mixing [5]. If adopting the real-time ethanol and diesel mixing, it is necessary to install the real-time mixing device on the engine, and it is hard to control the mixing ratio [6].

It is a more common form that ethanol is injected into the inlet and ignited by burning diesel after mixed gas was formed in the cylinder. However, the variation of ethanol entering the cylinder between the different work cycles is significant, the non-uniformity between the cylinders of the multi-cylinder engine is also significant [7]. 
The ethanol can also be applied with homogenous charge compression ignition mode for application in the diesel engine. In case of ethanol injection in the inlet or the cylinder, higher compression ratio and higher inlet temperature can be used for higher pressure and temperature in the cylinder, so the ethanol mixture automatically ignites and combusts $[8,9]$.

Fang Xianzhong, et al. of Jilin University conducted the ethanol - diesel direct injection study. Ethanol injection and diesel injection was respectively injected with the original injection system and the new mechanical pump injection system. The ethanol injection starting point is $1^{\circ} \mathrm{CA}$ behind the diesel injection starting point, diffusion accounts for the main part during ethanol combustion, and $\mathrm{HC}$ and $\mathrm{CO}$ emissions significantly increase when compared with the original diesel engine $[10,11]$.

Therefore, An electronic control gasoline injection system was installed on the single cylinder diesel engine, adopt diesel injection by the original pump injection system, with the initial injection moment at $344^{\circ} \mathrm{CA}$, and ethanol injection by the electronic control injection system, with overlapped injection period between ethanol and diesel injection, for initial injection moment at $344^{\circ} \mathrm{CA}, 338^{\circ} \mathrm{CA}, 332^{\circ} \mathrm{CA}, 326^{\circ} \mathrm{CA}$ and $320^{\circ} \mathrm{CA}$ respectively. FIRE software was used to establish a $3 \mathrm{D}$ combustion model, so as to study the impact of different injection starting points on the mixed ethanol formation and combustion process of the ethanol - diesel direct injection engine when the ethanol injection starting point is earlier than the diesel injection starting point.

\section{Establishment of the combustion model}

The TDC (top dead center) geometric model of the combustion chamber is drawn by ProE software and divided by Hypermesh software, and then checking, adjustment and refining of the mesh are performed in AVL FIRE. The calculation and post-processing analysis are carried out after the dynamic mesh and the sub-models are set.

The engine parameters needed to build the model are shown in Table 1 . The physical and chemical parameters of the ethanol and diesel of the software are adopted.

Table1. Summary of engine specifications

\begin{tabular}{|c|c|}
\hline Parameters & Value \\
\hline Туре & $\begin{array}{l}\text { Vertical, air cooled, natural aspirating, direct } \\
\text { injection, four-stroke }\end{array}$ \\
\hline Cylinder bore $\times$ stroke $/ \mathrm{mm} \times \mathrm{mm}$ & $88 \times 75$ \\
\hline Length of the connecting rod $/ \mathrm{mm}$ & 115 \\
\hline Compression ratio & 20.8 \\
\hline Rated rotation speed $/ \mathrm{r} \cdot \mathrm{min}^{-1}$ & 3000 \\
\hline Combustion chamber type & Type $\omega$ \\
\hline $\begin{array}{l}\text { Diesel supply advance angle ( }{ }^{\circ} \mathrm{CA} \text { in } \\
\text { front of TDC) }\end{array}$ & 21 \\
\hline Inlet valve closing ( ${ }^{\circ} \mathrm{CA}$ behind BDC) & 54 \\
\hline $\begin{array}{c}\text { Exhaust valve open ( }{ }^{\circ} \mathrm{CA} \text { in front of } \\
\text { BDC) }\end{array}$ & 54 \\
\hline $\begin{array}{c}\text { Number of nozzles of the diesel } \\
\text { injector }\end{array}$ & 4 \\
\hline $\begin{array}{l}\text { Diameter of nozzles of the diesel } \\
\text { injector/mm }\end{array}$ & 0.32 \\
\hline $\begin{array}{c}\text { Number of nozzles of the ethanol } \\
\text { injector }\end{array}$ & 6 \\
\hline $\begin{array}{c}\text { Diameter of nozzles of the ethanol } \\
\text { injector/mm }\end{array}$ & 0.183 \\
\hline
\end{tabular}

The diesel injector has 4 uniform holes, and the ethanol injector has 6 non-uniform holes. As the angle between the hole injection direction of two injectors and the cylinder section is inconsistent, the whole combustor chamber is adopted for modeling. The injection location and fuel spray distribution are shown in Figure 1. In order to describe the nephogram post-processing of the example, two sections are defined (Section A passes through the diesel injector center and Section $\mathrm{B}$ passes through the ethanol injector center, these two sections are the symmetrical sections of the 
injection fuel spray), and the following nephograms are taken from these two sections. The area close to the nozzle and boundary is densified, with 110,496 meshes at TDC and 348,096 meshes at BDC (bottom dead center). The geometric model and combustion chamber mesh are shown in Figure 2.

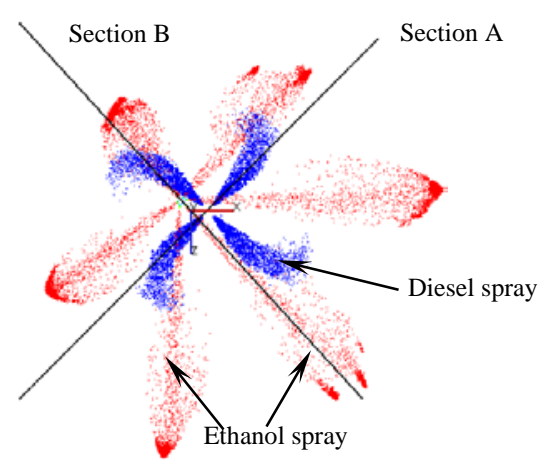

Figure 1. Diesel and ethanol injection position and fuel spray

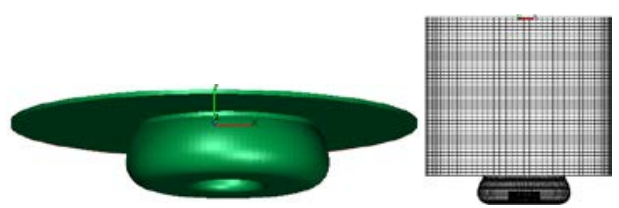
a) top dead center
b) bottom dead center

Figure.2 Geometric model at top dead center and combustion chamber mesh at bottom dead center

The kinetic calculation of chemical reaction is carried out with FIRE's own standard ethanol and diesel transportation model, and the main computational model selection is shown in Table 2 .

Table 2. Computational models

\begin{tabular}{cc}
\hline Computational Model & Selection \\
\hline Turbulence model & K-Zeta-F \\
Fuel wall interaction & Bai Gosman \\
model & Multi-component \\
Fuel evaporation model & KHRT \\
Fuel spray breakup & model \\
Combustion model & Coherent Flame Model \\
Self-ignition model & Two-Stage \\
Nitrogen oxide model & Extended \\
Soot model & Zeldovich+prompt+fuel \\
\hline
\end{tabular}

The combustion model is used to simulate five conditions featured by the simultaneous diesel and ethanol injection (with ethanol injection starting point earlier than the diesel injection starting point) with the ethanol injection starting points at $344^{\circ} \mathrm{CA}, 338^{\circ} \mathrm{CA}, 332^{\circ} \mathrm{CA}, 326^{\circ} \mathrm{CA}$ and $320^{\circ} \mathrm{CA}$. In order to facilitate subsequent analysis, the five conditions are respectively marked as E0, E6, E12, E18 and E24 (E means earlier ethanol injection, and the number means the crankshaft rotation angle between the initial ethanol injection moment and the initial diesel injection moment. For example, E0 means the same initial ethanol/diesel injection point). If the ethanol injection duration is $24.6^{\circ} \mathrm{CA}$, even in case of E24, the diesel injection will start prior to the ethanol injection completion. In other words, though the ethanol injection starting points in five conditions are different, there is overlapped period between the ethanol injection and the diesel injection. 


\section{Combustion Simulation Results and Analysis}

Figure 3, Figure 4, Figure 5 and Figure 6 show the cylinder pressure, combustion heat release rate, average temperature in the cylinder, NO mass fraction and Soot mass fraction under conditions of five ethanol injection starting points.

\subsection{Cylinder Pressure and Combustion Heat Release Rate}

The pressure curve in Figure 3 shows that, in case of the overlapped ethanol/diesel injection period, if the ethanol injection is earlier, the cylinder pressure slightly reduces firstly, and then rapidly increases. The higher the pressure rise rate is, the higher the maximum combustion pressure, and the headmost the corresponding phase of the maximum combustion pressure will be. In the post-combustion phase, the earlier the ethanol injection is, the slightly lower the cylinder pressure will be. However, the difference between the cylinder pressure in these five conditions is small.

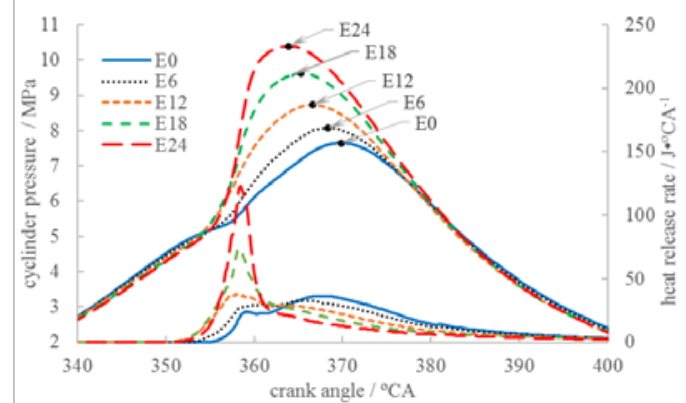

Figure 3. Cylinder pressure and combustion heat release rate

The combustion heat release curve in Figure 3 shows that the combustion heat release starting point of E12, E18 and E24 is almost the same. All of them are earlier than that of E6, and the combustion heat release starting point of E0 is the latest. Earlier initial ethanol injection will bring steeper heat release rate curve during the initial combustion period, higher peak value, shorter heat release duration, more combusted fuel during the rapid combustion period, and more concentrated heat release. The difference of the heat release rate of E0, E6 and E12 is relatively small, because the heat release period of E12 is earlier, the cylinder pressure is higher. Combustion heat release rules of E0 and E6 have obviously shown the double-peak characteristics, with the increased fuel diffusion combustion proportion [12]. The later the ethanol injection starting point is, the more serious the post-combustion phenomenon will be. In the future study, the diesel and ethanol injection advance angle can be increased properly.

\subsection{Average Temperature in the Cylinder}

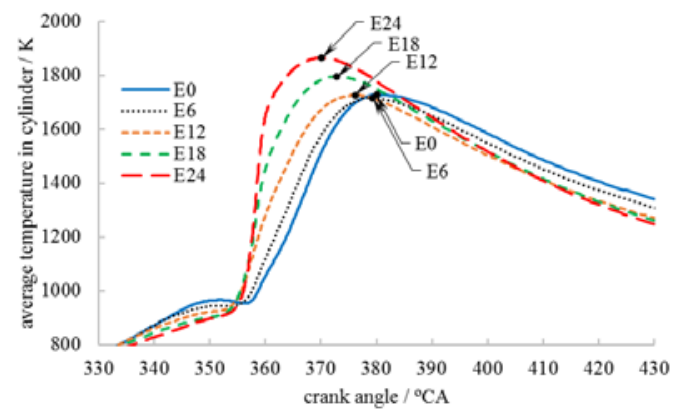

Figure 4. Average temperature in the cylinder

Figure 4 shows that, earlier ethanol injection starting point will bring earlier ethanol endothermic gasification, making the temperature curve of the cylinder during compression lower. However, if the longer time is left for the ethanol gasification before the diesel ignition, so the mixed ethanol will be more, and the spatial distribution will be wider. In case of the diesel ignition, the ethanol can quickly participate in the combustion. During the rapid combustion stage, the earlier the ethanol injection starting point is, the faster rise of the temperature curve of the cylinder and the earlier the corresponding phase of the highest average temperature in the cylinder will be. Viewing from the 
maximum average cylinder temperature, E24 is significantly higher than other conditions, followed by E18. The maximum average temperature difference of E12, E6 and E0 is small, but E6 has the lowest value. In the post-combustion stage, earlier ethanol injection starting point will bring lower average temperature of the cylinder, which is mainly caused by increased heat transfer loss to the cylinder owing to the higher combustion temperature in the cylinder during the rapid combustion stage [13].

\subsection{NO Concentration}

Figure 5 shows that, except E0, the earlier the ethanol injection starting point is, the steeper the NO curve and the larger the NO generation will be. The E0 curve is similar to E6 curve, and for E6, the mixed ethanol participating in the initial combustion period is slightly more, and NO generation is slightly larger. Figure 3 shows that, both of them have the obvious double concentrated heat release periods. As the second concentrated heat release period of E0 has larger heat release and longer duration, NO generation in the post-combustion period is higher than that of E6. After the concentrated heat release period, NO generation shows a frozen situation. Figure 4 and Figure 5 show that, NO generation corresponds to the highest average temperature in the cylinder, and higher average temperature in the cylinder brings higher NO concentration.

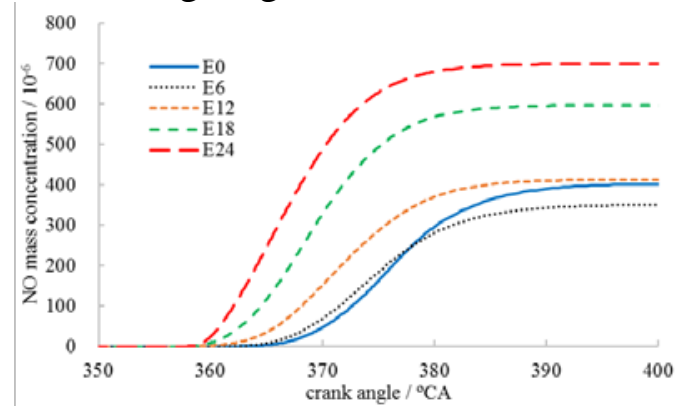

Figure 5. NO mass concentration in the cylinder

\subsection{Soot Concentration}

E12 has the lowest soot generation, E0 has the highest soot generation, followed by E24, indicating that the condition that the ethanol injection starting point is earlier than the diesel injection starting point properly is the most favorable for reducing soot generation.

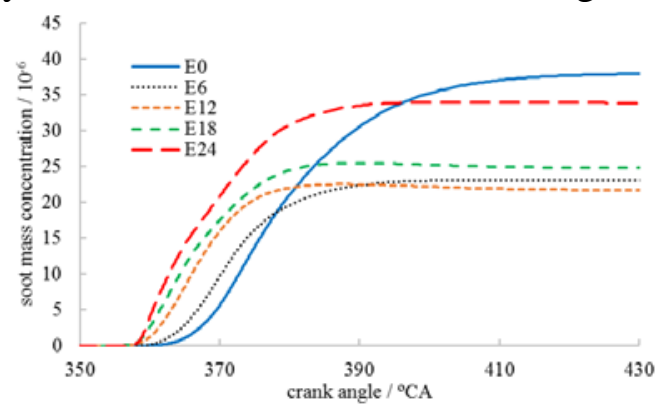

Figure 6. Soot mass concentration in the cylinder

The soot generation condition is high temperature and lack of oxygen. For E24, after the diesel injection and ignition, a lot of mixed ethanol will burn quickly, and temperature and pressure in the cylinder will have a rapid rise. If the subsequent diesel injection is filled into the high temperature ethanol flame, more diesel spray will be sintered to soot particles without evaporation and atomization.

For E0, as ethanol and diesel injection in the cylinder is carried out at the same time, the cylinder pressure and temperature are higher than those of other four conditions. On one hand, higher cylinder pressure will reduce the ethanol spray penetration distance, on the other hand, higher temperature will accelerate the ethanol gasification, and increase the concentration of the mixed ethanol close to the central area of the cylinder. In addition, as the space distribution area is relatively small, for diesel injection at the same time, the evaporation and atomization and mixed 
gas formation process will be affected, thus making E6 and E0 have a later ignition starting point. After the ignition, as the mixed ethanol distribution degree is low, it is not enough for the oxygen utilization of the whole cylinder. In addition, as the local anoxic environment is formed near the center of the combustion chamber, the subsequent diesel will be located in the anoxic environment. With the increase of heat released due to ethanol diffusion and combustion, high temperature will be formed in the area, thus resulting in increased soot generation.

\subsection{Discussion and Analysis}

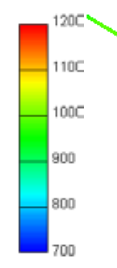

Temperature

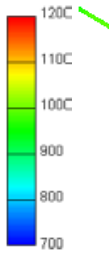

Temperature

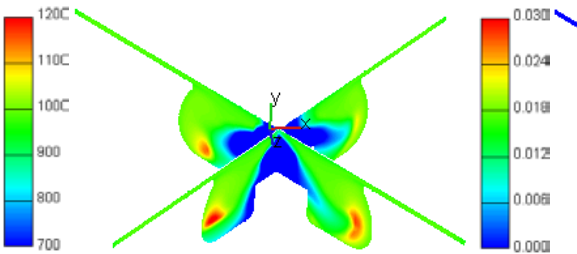

Temperature

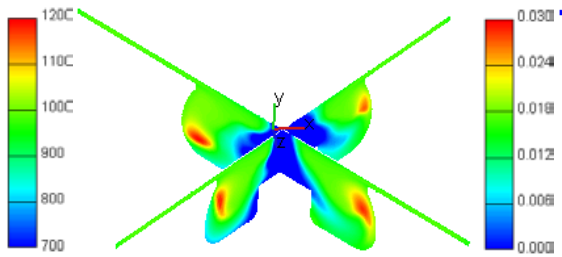

Temperature

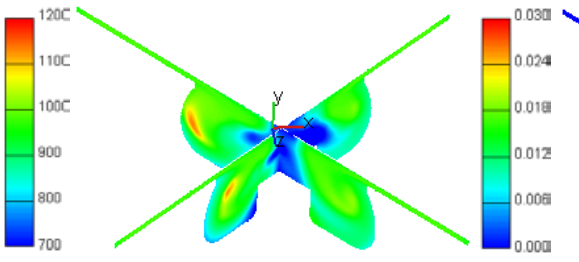

Temperature diesel mass concentration

c) $\mathrm{E} 12$ at $353.5^{\circ} \mathrm{CA}$ a) $\mathrm{E} 0$ at $356^{\circ} \mathrm{CA}$

ethanol mass concentration
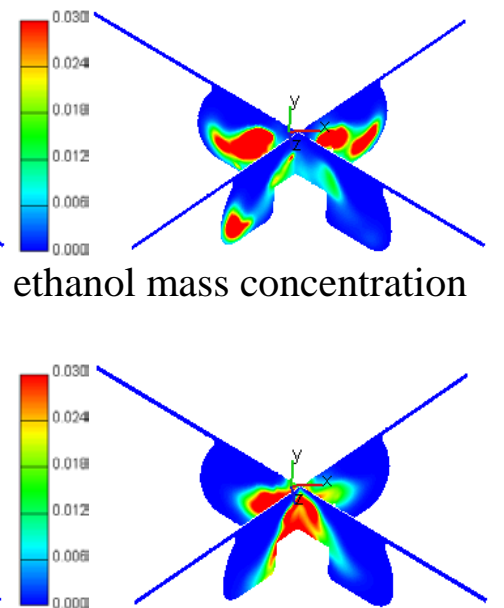

ethanol mass concentration

b) $\mathrm{E} 6$ at $354^{\circ} \mathrm{CA}$
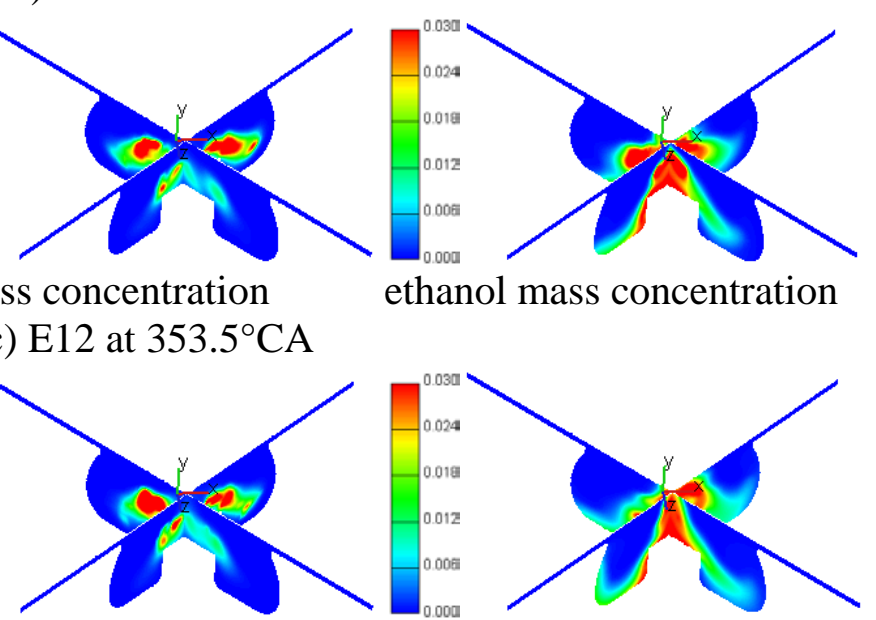

ethanol mass concentration

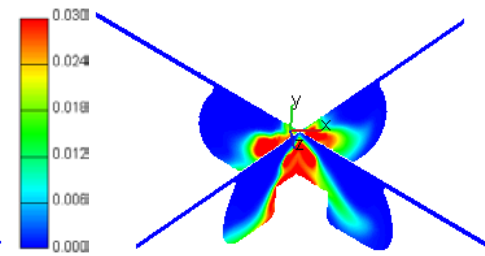

ethanol mass concentration

d) E18 at $353.5^{\circ} \mathrm{CA}$
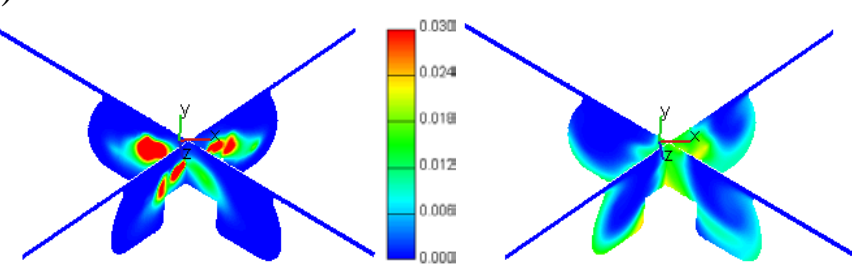

ethanol mass concentration

e) E24 at $353.5^{\circ} \mathrm{CA}$

Figure 7. Temperature distribution and diesel and ethanol mass concentration with different ignition starting point

The earlier the ethanol injection starting point is, the lower the pressure and temperature of the cylinder at the corresponding moment will be. Lower pressure in the cylinder and higher penetration speed during the ethanol injection will bring smaller spray cone [14]. When the temperature is low in the cylinder during the ethanol injection, the evaporation will slow down. Earlier spraying will bring wider space distribution of the mixed ethanol, and higher utilization rate 
of the gas in the cylinder. In contrast, later ethanol injection will make the distribution of the mixed distribution more concentrated in the surrounding area of the injector, thus making the oxygen concentration of the area lower.

Figure 7 shows the temperature in cylinder, and distribution of diesel mass fraction and ethanol mass fraction for all combustion starting point (the section is Section A where the diesel spray is located and Section B where the ethanol spray is located as shown in Fig. 2). Earlier ethanol injection starting point will bring the more combustible mixed gas, the wider space distribution area, and the uniform concentration gradient [15]. Upon the diesel injection, the ethanol injection will be ended, the diesel evaporation and atomization will be slightly affected for proper mixing with the air, thus forming mixed gas and ignition. When the advance value of the ethanol injection starting point is reduced, the impact of the concentration and space distribution of the components of the ethanol on the diesel spray evaporation will be increased, thus slighting delaying the ignition starting point [16]. The temperature area with $1100 \mathrm{~K}$ in the cylinder will be made as the ignition condition, namely, E0 is applied with $356^{\circ} \mathrm{CA}$, E6 is applied with $354^{\circ} \mathrm{CA}$, and E12, E18 and E24 are applied with $353.5^{\circ} \mathrm{CA}$.

Figure 7 shows that, the first burning area is located in the outer layer of earlier spraying diesel. The diesel in this part stays the longest in the cylinder and its contact with the air is the most sufficient, therefore, it is easy to form premixed gas. In addition, along with the diesel heating and evaporation, it absorbs the gas heat of involved areas and cools down the fuel spray center. However, as the gas in the outer layer of the fuel spray has higher temperature, the outer layer of earlier spraying diesel reaches the burning conditions firstly. The comparison between temperature and ethanol concentration shows that, the initial burning area is of lower ethanol concentration, however, its surrounding area is of gradually-increasing ethanol concentration, which shows that the burning diesel immediately ignites the ethanol in this area, and then diesel in a number of places burns and ignites the mixed ethanol. In addition, the spread of flame can also result in mixed ethanol combustion. [17].

In case of earlier ethanol injection starting point, the ethanol distribution area during ignition period will be wider, the mixed gas will be more uniform, the mixed gas concentration will be in an easier combustion area, and the combustion speed and flame spread speed are higher, showing obvious premixed combustion characteristics [18]. In case of the later ethanol injection starting point, the ethanol diffusion and combustion will be carried out upon injection after ignition, and the diffusion combustion proportion will increase.

\section{Conclusion}

Five conditions featured by the simultaneous diesel and ethanol injection (with ethanol injection starting point earlier than the diesel injection starting point) are calculated and analyzed with the established 3D combustion model. The following conclusions can be drawn based on the structure characteristics of the engine and the installation position of fuel injectors of the engine and the injection angle of the holes:

(1) The earlier the ethanol injection is, the steeper the heat release rate curve during the initial combustion period, the higher the peak value, and the shorter the heat release duration, the higher the maximum combustion pressure and the headmost phase of the maximum combustion pressure are, and the more obvious the premixed combustion is.

(2) The earlier ethanol injection starting point is, the quicker rise of the cylinder temperature curve, the headmost phase of the highest average temperature, and the higher average temperature in the cylinder and the higher NO concentration are.

(3) The ethanol injection starting point shall be earlier than the diesel injection starting point injection, for it is the most favourable for reducing soot generation. 


\section{Acknowledgments}

This research is funded by the National Natural Science Foundation of China (No.51366002) and key project of educational science planning of Guizhou Provincial Education Department (No.2014A065) and key construction projects of the first class University (phase I) of Guizhou Province in 2017- the first class course. Special thanks should go to Liying Zhou who is the corresponding author of this paper.

\section{References}

[1] Jikun Huang, Huangguang Qiu, Michiel Keyzer, et al. Impacts of bioethanol development on China's regional agricultural development [J]. China Ecomomic Quarterly, 2009,8(2):727-742. (in Chinese with English abstract)

[2] Wang Xiaojuan, Feng Hao, Wang Bin, et al. Investigation of two-step pretreatment method for production of ethanol from lignocellulosic biomass [J]. Transactions of the Chinese Society of Agricultural Engineering, 2012, 2012,28(5):194-200. (in Chinese with English abstract)

[3] Fu Chang, Wu Fangwei. The estimation of producing potential of fuel ethanol and its developing strategy in china [J]. Journal of Natural Resources, 2014,29(8):1430-1440. (in Chinese with English abstract)

[4] KRG And, GJ Suppes. Miscibility of ethanol in diesel fuels [J]. Industrial \& Engineering Chemistry Research, 2001, 40(3):949-956.

[5] Datta A, Mandal B K. Impact of alcohol addition to diesel on the performance combustion and emissions of a compression ignition engine [J]. Applied Thermal Engineering, 2016, 98: 670682.

[6] He Bangquan, Wang Jianxin, Yan Xiaoguang, et al. Combustion and emission characteristics of engines using ethanol-diesel fuels blended on line [J]. Journal of Tsinghua University Science and Technology, 2003, 43 (11) : 1523-1525,1541. (in Chinese with English abstract)

[7] Ma Yupo, Liu Fushui, He Xu, et al. Visualization of combustion characteristics of intake port injected ethanol ignited by diesel fuel [J]. Transactions of CSICE, 2014,32 (4) : 296-301. (in Chinese with English abstract)

[8] ML Botero, Y Huang, DL Zhu, et al. Synergistic combustion of droplets of ethanol, diesel and biodiesel mixtures [J]. Fuel, 2012,94(1):342-347.

[9] S Natarajan, MA Kumar, AUM Sundareswaran. Computational analysis of an early direct injected HCCI engine using bio ethanol and diesel blends as fuel [J]. Energy Procedia, 2017,105:350-357.

[10] Fang Xianzhong, Liu Xunjun, Liu Zhongchang, et al. Performance comparison between diesel-methanol injection and diesel-ethanol injection with dual injection system in a DI compression ignition engine [J]. Transactions of CSICE, 2004,22 (6) : 514-517. (in Chinese with English abstract)

[11] Fang Xianzhong, Liu Xunjun, Li Guoliang, et al. Development of compression ignition test engine with dual direct injection systems [J]. Journal of Jilin University ( Engineering and Technology Edition ), 2005,35 (1) : 34-38. (in Chinese with English abstract)

[12] M. Farias, J. F. Schlosser, A. Russini, et al. Performance of an agricultural engine using mineral diesel and ethanol fuels [J]. Ciencia Rural, 2017, 47(3):1-6.

[13] VB Pedrozo, I May, H Zhao. Exploring the mid-load potential of ethanol-diesel dual-fuel combustion with and without EGR [J]. Applied Energy, 2017, 193:263-275. 
[14] L.-Y. Zhou, S.-F. Dong, H.-F. Cui, et al. Measurements and analyses on the transient discharge coefficient of each nozzle hole of multi-hole diesel injector [J]. Sensors \& Actuators: A. Physical, 2016, 244: 198-205.

[15] CD Rakopoulos, KA Antonopoulos, DC Rakopoulos, et al. Multi-zone modeling of combustion and emissions formation in DI diesel engine operating on ethanol-diesel fuel blends [J]. Energy Conversion \& Management, 2008,49(4):625-643.

[16] D. Simsek, E. Vural, S. Ozer, et al. Model analysis of the effect of ethanol blended diesel fuels in diesel engines on ignition delay and combustion [J]. International Journal of Scientific Research in Science and Technology, 2017 3(4):47-54.

[17] Prashant G K, Lata D B, Joshi P C. Investigations on the effect of ethanol blend on the combustion parameters of dual fuel diesel engine[J]. Applied Thermal Engineering, 2016, 96: 623-631.

[18] Sjoberg M, John E. Ethanol autoignition characteristics and HCCI performance for wide ranges of engine speed, load and boost [J]. international Journal of Engines, 2010,3 (1) : 84-106. 